\title{
A Hunt for the Urban Tectonic: Deriving Relevant Urban Architecture from the Existing Fabric of our Cities and Communities
}

\author{
WILLIAM J. DORAN \\ Louisiana State University
}

The urban tectonic can be defined as the way cities and communities are constructed from multiple pieces - objects, forces, people, and meanings - interwoven into a larger whole of overlapping systems. Even though it is the ultimate destination of everything we create as architects, we often take for granted the way this interwoven fabric, or urban tectonic, is designed ... or not designed. It is hyper-relevant to and significantly impacted by our work - and should thus stand as an important facet of architectural education. How do we teach our students to look beyond the physical things we see and create as architects, to consider the underlying fabric of the urban tectonic?

\section{APPROACHING A MORE RELEVANT PRACTICE AND PEDAGOGY}

While function, economy, and beauty endure as sentries of contemporary architecture, they are quickly being eclipsed at a global scale by complex issues faced by rapidly growing urban areas. In a 2011 article for The Atlantic, the iconic urbanist Richard Florida shares some numbers on the urbanization of the world.

Our species is well on its way to becoming Homo urbanus. Consider that just two centuries ago, only 3 percent of the world's population lived in cities. [...] Today, it's exploded to more than half the world's population. And by the year 2030, more than five billion people will live in cities and urban centers. ${ }^{1}$

Increasing density, more diverse populations, and swiftly changing social, economic, and environmental conditions overshadow architecture as a professional service led by the largess of governments and the private market. Our discipline risks losing relevance if its creative potential is not leveraged to engage these pressing issues and participate in a conversation that expands beyond its traditional role. In education, most projects are predominantly theoretical or conceptual exercises that overlook the issues of the urban tectonic present in the communities where we teach and work. Could the actions, relationships, and experiences of the city drive the way we select sites, develop programs, and build the financial and social capital that sustain architecture? Integrating these things into the design challenge has the potential to make our practice much more relevant and inclusive - attuned to the wisdom of the places we work and the people who live there as non-traditional, but fruitful sources of design intelligence. It allows our work to engage real-world problems and interact with the active political, social, economic, and environmental systems that play out in the urban tectonic.

In this light, the urban tectonic is not a blank slate onto which we can draw plans or place projects. Rather, it is the most important material from which to develop our work.

...architecture and civilization develop hand in hand [...] there is little use in discussing the needs and promises of architecture without relating the shell [the building] itself to the informing changes that may or may not take place in the life of the community itself. ${ }^{2}$

In 2012, the Austin Center for Design published a book called Wicked Problems, designed to wake up the world's creative minds to the very real problems we face today:

A wicked problem is a social or cultural problem that is difficult or impossible to solve for as many as four reasons: incomplete or contradictory knowledge, the number of people and opinions involved, the large economic burden, and the interconnected nature of these problems with other problems. Poverty is linked with education, nutrition with poverty, the economy with nutrition, and so on. These problems are typically offloaded to policy makers, or are written off as being too cumbersome to handle en masse. Yet these are the problems-poverty, sustainability, equality, and health and wellness - that plague our cities and our world and that touch each and every one of us. These problems can be mitigated through the process of design... ${ }^{3}$

In contemporary practice, we often take the economic and socio-political processes that drive the production of architecture as an unchallenged set of givens. The most significant developments in architecture through history have followed wealth, power, and resources - regardless of the aims, means, or consequences (profit, slave labor, excessive use of natural resources, unbridled suburban expansion). We take for granted the way architecture is created within the context of our society. While the design of the built environment shapes the lives of everyone, standard architectural practice - and often the way we train our students - overlooks its profound impact on the nature of our cities and communities. Most firms follow a top-down model driven by the free market - serving governments, 
businesses, developers, or wealthy individuals - with a client approaching a designer for services with a site, funding, and list of needs already determined. As responsible designers and as citizens - it is our job to question this process and the privilege it bestows on clients, revenue, and our own design portfolios to make decisions about the fabric of our cities and communities.

Architect Juhani Pallasmaa rather momentously describes architecture as the "primary instrument in relating us with space and time [...] giving these dimensions a human measure to be tolerated, inhabited and understood by humankind."4 Architecture has a unique and integral relationship between us and the larger world. The way we construct things reveals some aspect of how we are while also revealing aspects of the world around us. He continues, "A building frames, articulates, restructures, gives significance, relates, separates and unites, facilitates and prohibits. ${ }^{5}$ It creates a narrative as it facilitates the physical and metaphysical ordering and understanding of our environment. It is a window out to the world around us - but it is also a window into ourselves.

In this way, architects are not only responsible for creating physical structures that organize and facilitate daily life, but they are also confronted with the precarious task of saying something about how we live and work - how we treat the environment and one another. Without this critical lens, it is easy to detach ourselves from the weight architecture brings to bear on the social, cultural, environmental, and economic problems confronted by our world today - the very structures and systems our work inhabits, reinforces, or potentially challenges.

\section{DEFINING THE URBAN TECTONIC}

urban $^{6}$, adj.-- $^{-}$

1a. relating to, situated or occurring in, or characteristic of, a town or city, esp. as opposed to the countryside;

b. that constitutes or includes (part of) a town or city

tectonic ${ }^{7}$, adj. or n.--

* Late Latin tectonicus, from Greek tektonikos of a builder

* etymologically related to Latin texo: to weave, to interlace, to write; textile, cloth, textus, web, text, textura, building and contextus or context

* (in architecture) refers to the way something is constructed from multiple pieces - connecting components to make a larger whole

In linking these two definitions, we can define the urban tectonic as the way cities are constructed from multiple pieces - connecting components to make a larger whole. Those components are an overlapping constellation of

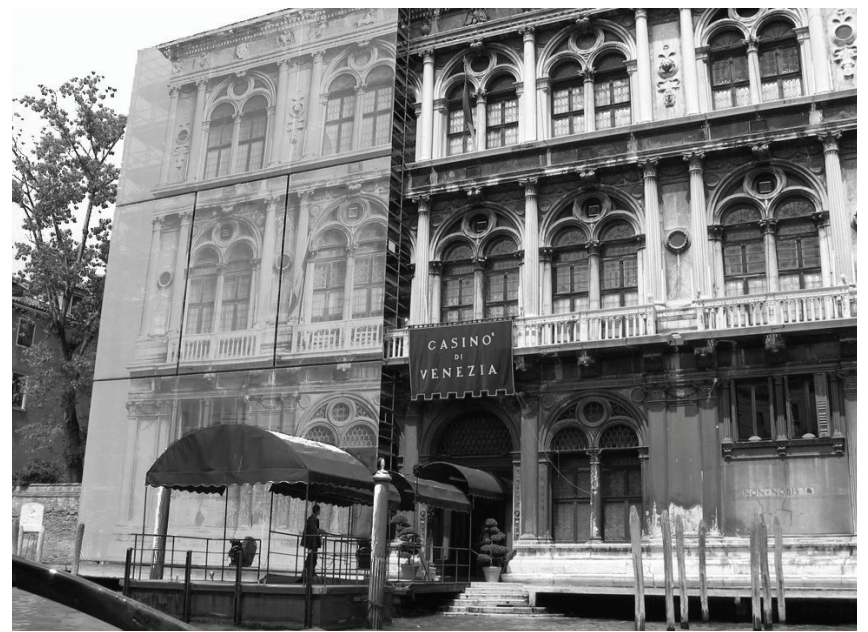

Figure 1: Photo of the Casino di Venezia in Venice, Italy undergoing renovations behind scaffolding wrapped in an image of the building. ${ }^{8}$

systems - from building stock, infrastructure, socio-political constructs, cultural traditions, and social relationships to watersheds and animal habitats. All of these things intersect and influence on another. We as the city's inhabitants are an integral piece of the puzzle - the urban tectonic. We are also, largely, its creators. It is fabricated as much with our hands, machines, and technology as it is with our minds, through our relationships and experiences. Even the definition of the word fabricate means both to "make by assembling parts through art, skill, and labor"x and to "devise or invent (as a legend or lie)." ${ }^{\prime \prime}$ We fabricate both the physical environment in cities as well as truths or stories about that environment. In some cases we take this to the extreme, obscuring one kind of fabrication with the other (Figure 1).

Thus, the urban tectonic includes both physical and nonphysical constructions - both objects we can see in the city and the invisible or hidden systems and relationships (or mental constructions) that lay behind them.

Cities must be founded in the imagination as securely as they are founded upon the earth. ${ }^{10}$

Physical constructions in the urban tectonic include hard infrastructure such as roads, bridges, highways, and utilities. Electricity, gas, potable water, and storm water management systems are all part of the hard infrastructure of the city. This also includes the physical building stock of the city and the physical components of public transportation such as buses, bus stops, benches, and signage. It might also include physical boundaries such as levees, bodies of water, drainage ways, and highways and various forms of visible communication like signage in the public realm.

Non-physical constructions - or soft infrastructure - include things like bus routes, rules, and common courtesies of roads 


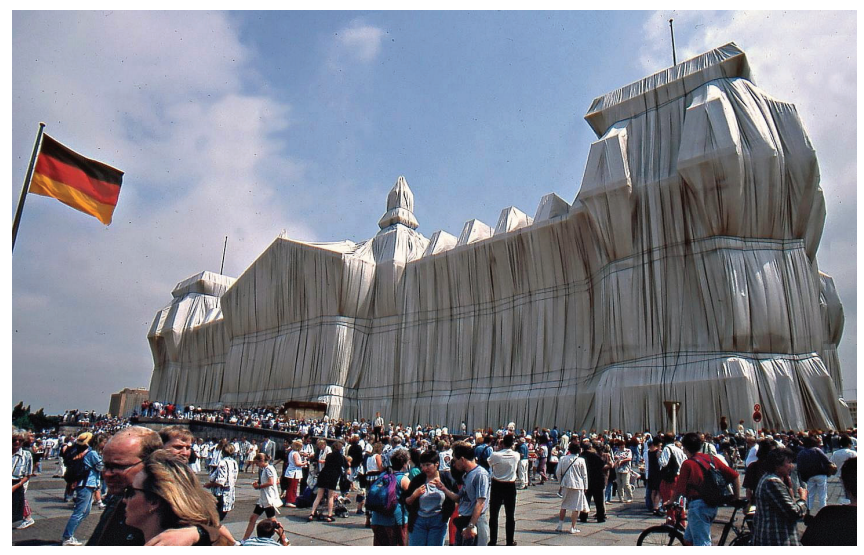

Figure 2: "Wrapped Reichstag" installation, 1971-1995, by artists Christo and Jean-Claude in Berlin. ${ }^{12}$

and sidewalks. Where, in cities, are we allowed to drive, bike, or walk? There are many invisible boundaries and borders that only show up on maps and in municipal zoning codes. Neighborhoods, districts, property lines, and even the concept of ownership itself fall into the world of the invisible. How do we know what is public space and what is private? Where are we allowed to go? Where do we feel comfortable going? Some of the most invisible, yet very much physically experienced constructions in our cities today, are racial and socio-economic boundaries that divide our communities.

\section{WHEN THE PHYSICAL AND THE NON-PHYSICAL CONNECT}

When we begin to connect the physical things to one another, to the non-physical, and to people and other actors in the city, we begin to see the larger-scale systems at play in the urban tectonic. Most physical constructions in the city represent, engage, or connect to non-physical constructions. Laws and law enforcement are an example of both physical and non-physical constructions directly tied to one another. The sounds and red and blue lights of emergency vehicles present to us the physical manifestation of the invisible, larger scale system of emergency management. The physical presence of a police vehicle or officer in uniform represents the very nonphysical laws of the land, which exist on paper or a computer server. We often see physical representations of non-visible or non-physical systems. The light and color of traffic signals or markings on the street remind us of the rules of the road. A fire hydrant presents a physical manifestation of fire control systems, just as a bus stop is the physical manifestation of the route and the city's public transportation system.

We can begin to play with the interaction between physical and non-physical constructions and meanings as a way to understand the city. Take, for example, the Wrapped Reichstag, by Christo and Jean Claude (Figure 2). The project took over twenty years to plan and execute (1971 - 1995). "Christo [and Jean-Claude] appeared to reawaken what he called the 'sleeping beauty' of the comatose Reichstag, with the gentle kiss of this diaphanous fabric."11 The wrapping of the physical manifestation of Berlin's Government in fabric is as much about the presence of something in people's minds as it is about the work standing up and existing as a physical construction. The fabric was removed when the new parliamentary government was established and the first session began. It marked a point in history and a change in the identity of the city. It was as much about the process and relationships it engaged as it was about appearance and experience.

\section{RESEARCH EXERCISE 1 AND 'THE DICTIONARY'}

As a research exercise, students were tasked with going out into the city to look for connections between the physical and the non-physical as a means to understand the urban tectonic. Students were assigned specific locations in the city and challenged to search for and photograph artifacts - any object made or modified by human workmanship as opposed to something formed by natural processes like a tree. After photographing what they saw, they were asked to connect the objects in their photos to other objects, actions, and people as a way to reveal larger-scale relationships, systems, and the meanings behind them. It challenged the way students look at the world by focusing on observation of physical objects and connecting them to non-physical systems and meanings.

The research product took the form of "A Dictionary of the Urban Tectonic." Each visible artifact and its hidden system became entries in the dictionary with a term, definition, and simple photo-diagram (Figure 3). Students were provided with consistent graphic requirements - using gray-scale photos as background, with highlighted artifacts, systems, and larger connections in color.

\section{WHEN PHYSICAL AND NON-PHYSICAL MIS-ALIGN OR CONFLICT}

Cities operate at two different levels. The conceptual frameworks (and their physical manifestations) that organize and control how the city and its inhabitants function; and the ordinary, informal practices of the everyday lived experience of the city. In other words, city-scale social, political, and economic structures and systems and the actions and practices that move around and within them. We see the conceptual framework of the city in the form of codes, laws, plans, and drawings. It is operated by governments, architects, and planners in pursuit of productivity. We see the everyday lived experience of the city, on the other hand, through the concrete spatial and material forms of the urban environment. It is the improvised, the practical, and the everyday movement of people within the city. To fully understand the urban tectonic, we must consider the "habits and practices of ordinary people"13 in addition to the "systems that give their lives meaning and identity."14 


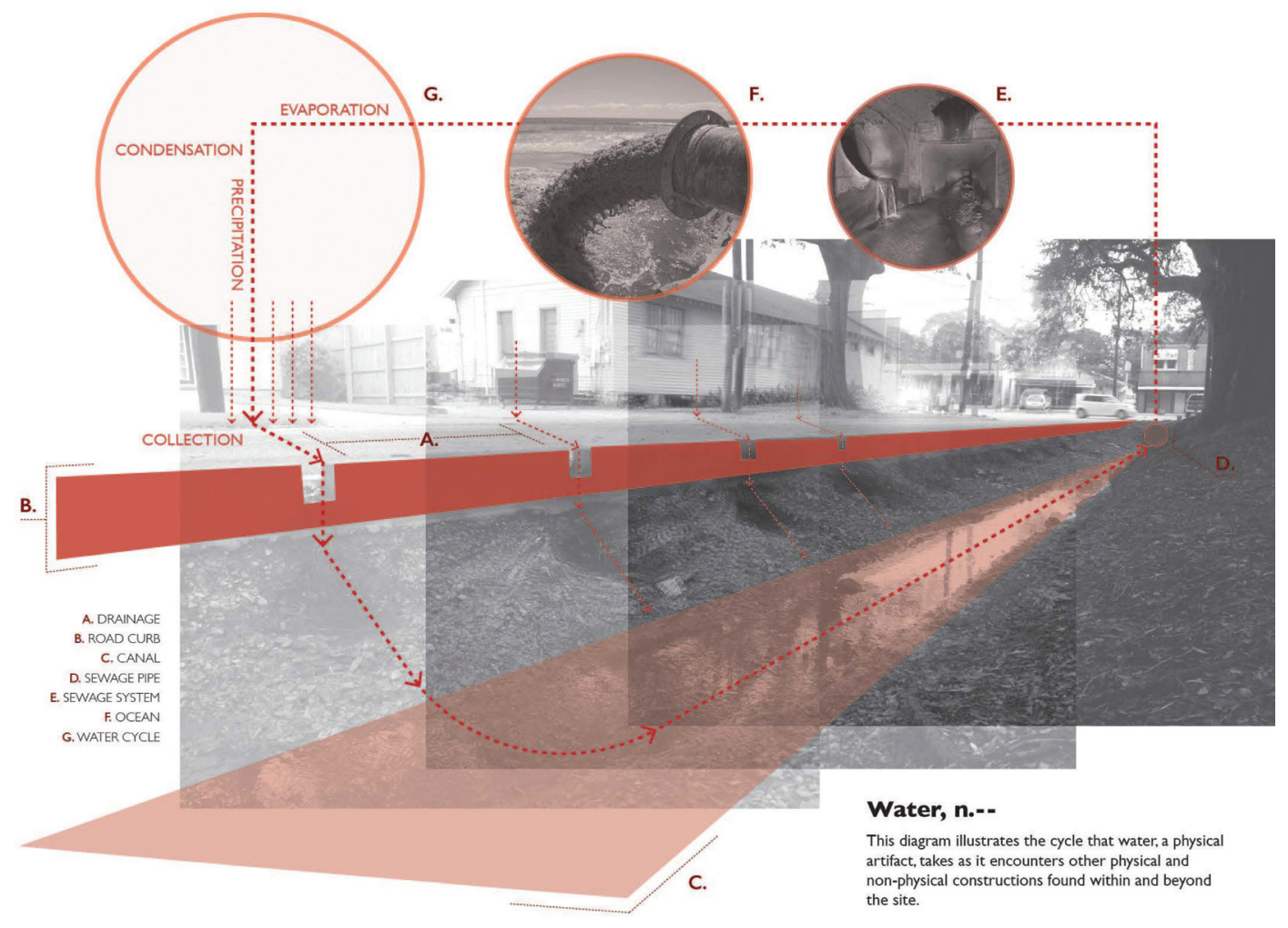

Figure 3: Student dictionary entry connecting a storm drain in a parking lot to larger stormwater drainage systems in the city and the hydrological cycle. Rebecca Maples, B. Arch, 2021.

When we look at the urban tectonic, we often find that the informal practices of the everyday do not directly align or comply with the larger-scale, planned systems of the conceptual city - physical practices that operate under the radar or in conflict with the non-physical. These everyday practices are valuable producers of space and sources of ingenuity and design expertise that may never be found through the lens of conceptual systems. They are an essential component of the urban tectonic and reveal diverse perspectives, values, and ways of communicating and operating in the city.

\section{RESEARCH EXERCISE 2: LEARNING FROM THE EVERYDAY}

This exercise challenged students to look for informal activities occurring in the city like ad-hoc homeless shelters or advertisements stapled to electrical poles. The purpose was to develop awareness of the everyday practices, actions, and spaces that conflict with (or exist underneath) the conceptual frameworks that shape our city-using the lens of conflict to identify subject matter. Students looked for spaces and actions that are unsanctioned, unplanned, improvised, or otherwise fall between the cracks - often uncategorized or unrecognized by the city. They divided into teams and went out to different locations in the city to complete the exercise. Each team developed a series of dictionary entries that defined different informal practices happening within the urban tectonic (Figure 4).

\section{THE CITY AS NARRATIVE}

As a physical place, cities are usually large tracts of land, relatively densely populated with building stock and located based on geographic advantage - near sources of food and water and/ or near a body of water to transport goods and people. They also take advantage of proximity and thus interaction interdependence, defense and control, and efficiency of scale and shared resources. But cities are much more than their physical characteristics and advantages. The city as narrative is a way of understanding the city through its people - their identity, actions, behaviors, beliefs, and history. The narrative is the story that holds the disparate parts of our lives in the physical world together. To fully understand the city, we must also strive to see it through the individual.

\section{RESEARCH EXERCISE 3: URBAN TECTONIC THROUGH NARRATIVE}

The final exercise required students to interview people engaged in simple urban activities like riding the bus or enjoying a public park. It challenged students to walk the streets of the city and uncover the stories of its inhabitants as a way of learning about and understanding the city as narrative, an important part of the urban tectonic. Students divided into teams and selected an activity from a provided list to conduct their research. After interviewing residents, the students were to identify a system, relationship, or other component of the urban tectonic embedded in the stories of the interviewees. Each identified element became a new entry into the dictionary (Figure 4). 

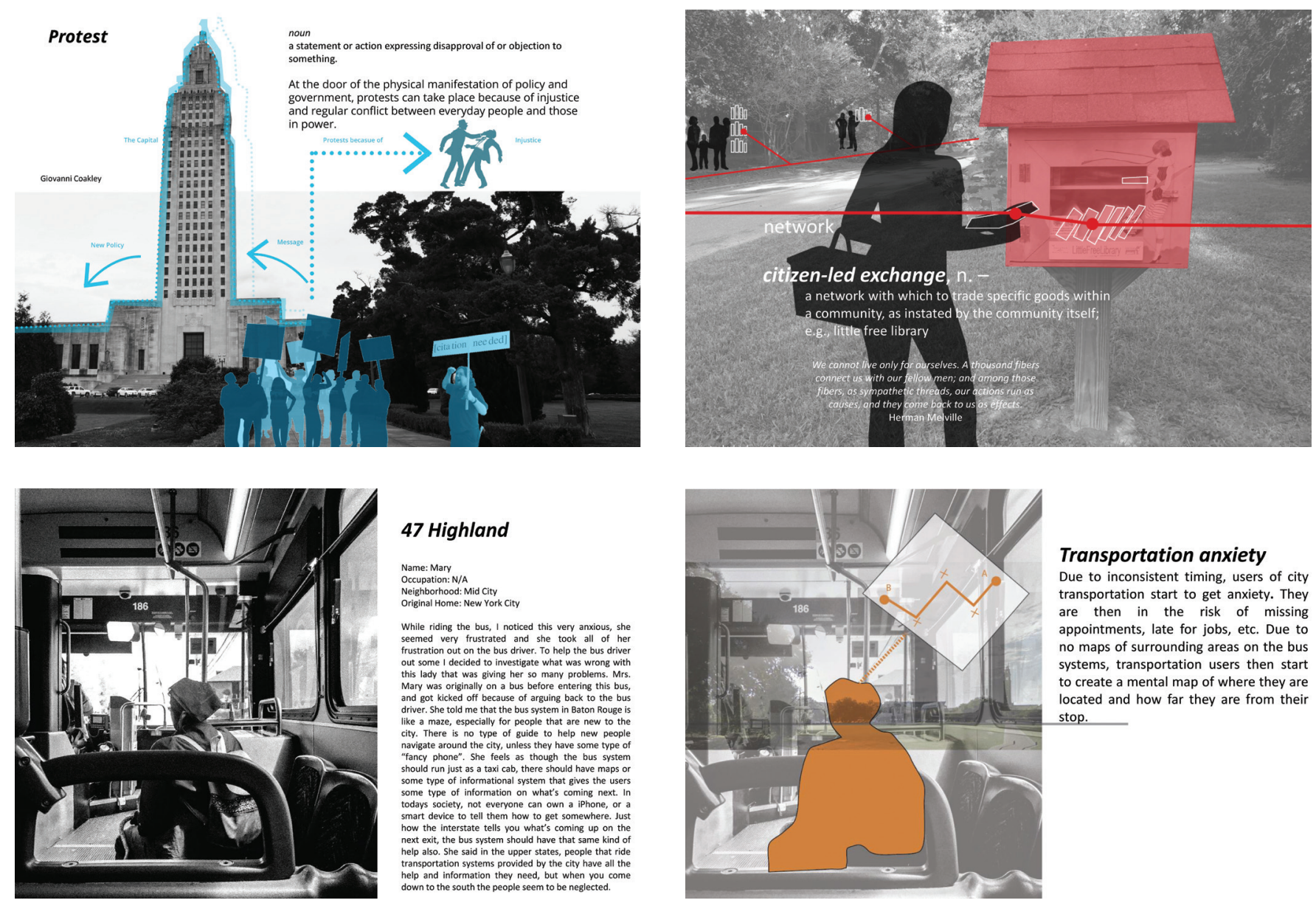

Transportation anxiety

Due to inconsistent timing, users of city transportation start to get anxiety. They are then in the risk of missing appointments, late for jobs, etc. Due to no maps of surrounding areas on the bus systems, transportation users then start to create a mental map of where they are located and how far they are from their stop.

Figure 4: Dictionary entries, top left to right: 'Protest' by Giovanni Coakley, B. Arch , 2018, and 'Citizen-Led Exchange' by Hayley Pugh, M. Arch, 2018 - examples of 'the everyday.' Bottom: Interview with 'Mary' on the city bus and subsequent dictionary entry 'Transportation Anxiety' by Brandon Slaughter, B. Arch, 2018.

\section{RELEVANT URBAN ARCHITECTURE + THE URBAN TECTONIC}

During the second half of the course, students were asked to identify and explore a specific problem from the research exercises to address with a small-scale design intervention. They created diagrams, maps, and transects to further document the problem they identified. The more specific the problem, the clearer an architectural solution became. Relevant and effective design solutions began to emerge like "Party in the Drain," which engaged residents in social events near or inside of major drainageways to educate the public and address a lack of awareness about stormwater infrastructure (Figure 5). "\#45Minutes" was a social media campaign designed to get feedback from bus riders about basic services they could take advantage of while enduring the long wait times for the city bus. A fresh produce 'food truck' concept was also developed to pop-up near bus stops and provide groceries, recipes, and prepared meals in areas with little access to grocery stores.

\section{CONCLUSIONS}

Exploring the process, motivation, and implications of engaging the urban tectonic of our cities and communities as a locus for design reveals an effective model for teaching students to look beyond the physical things they see or create. It connects them to the actions, relationships, and experiences of the city as primary drivers for architecture - the way we choose sites, develop programs, and build financial or social capital. It offers a new way of working that challenges practicing and future architecture to make an impact on social, economic, and environmental problems we face as a society.

\section{ENDNOTES}

1 Florida, Richard. "Why Cities Matter." City Lab. The Atlantic, September 2011

2 Mumford, Lewis. Sticks and Stones: A Study of American Architecture and Civilization. Dover Publications; Revised edition, 1955.

3 Kolko, Jon. Wicked Problems: Problems Worth Solving: A Handbook \& A Call to Action. AC4D, 2012.

4 Pallasmaa, Juhani. The Eyes of the Skin. Wiley, 2005.

5 Ibid.

6 "Urban." Merriam-Webster.com. Accessed December 10, 2017. https://www. merriam-webster.com/dictionary/tectonic. 


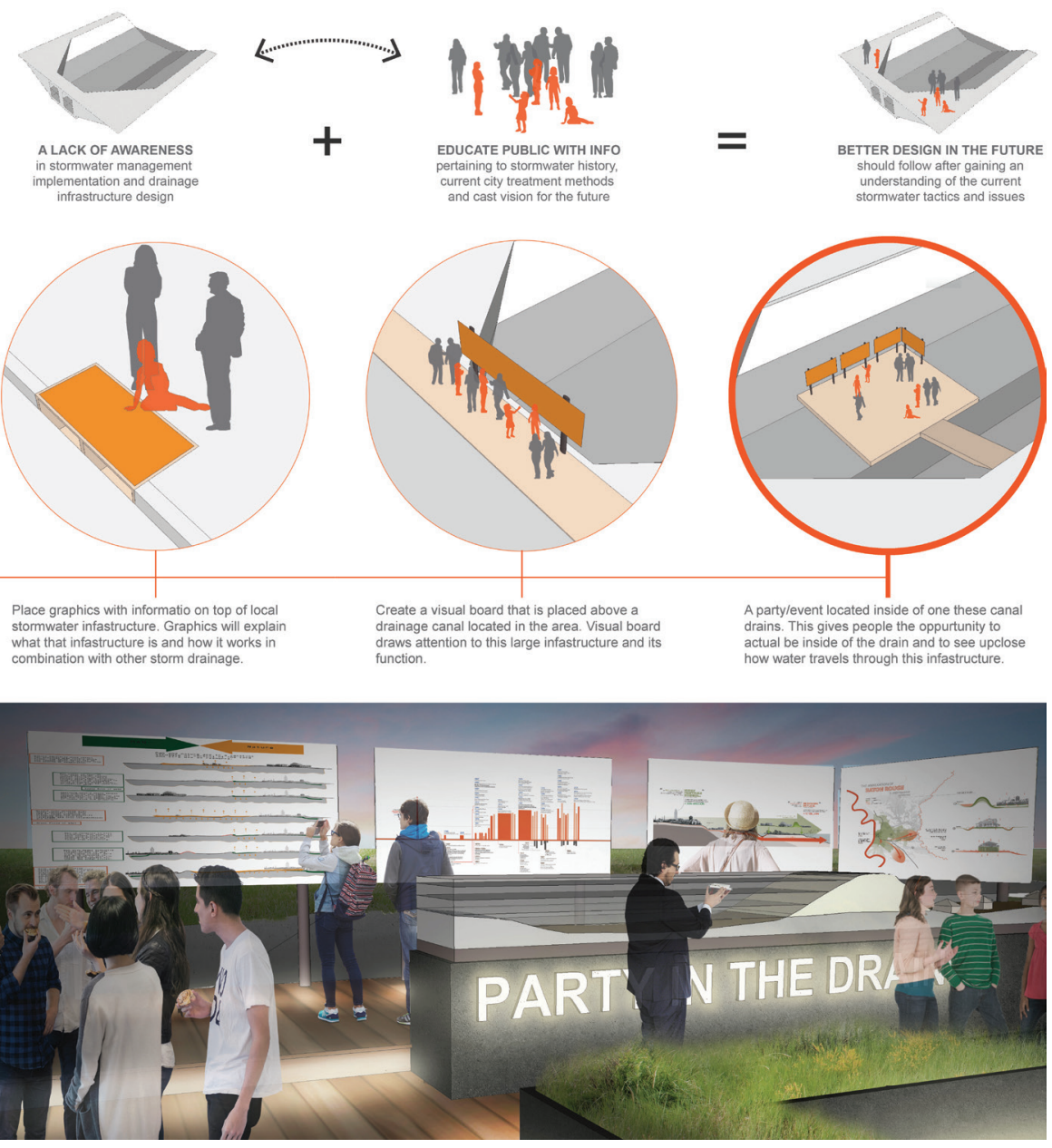

Figure 5: Portion of final design board showing a small-scale student design intervention called 'Party in the Drain,' Zach McLain, Kaitlyn Schuette, and Christopher Washington, B. Arch 2018.

7 “Tectonic." Merriam-Webster.com. Accessed December 10, 2017. https://www. merriam-webster.com/dictionary/tectonic.

8 Casino di Venezia, 1638, Venice, Italy. Source: 'roadmap,' 2006, Digital Image. Available from: https://www.panoramio.com/photo/25327751 (accessed January 2, 2018).

9 “Fabricate." Merriam-Webster.com. Accessed December 10, 2017. https://www. merriam-webster.com/dictionary/tectonic.

10 Willis, Daniel. The Emerald City and Other Essays on Architecture. Princeton Architectural Press, 1999.

11 Ibid.

12 Wrapped Reichstag by Christo and Jean Claude, 1971-1995. Source: flickr user txmx-2, 1995. Available from: https://www.flickr.com/photos/txmx-2/3715921978/ (accessed January 2, 2018)

13 Anderson, Nadia M. "Public interest Design as Praxis." Journal of Architectural Education, Volume 68, Issue 1, Taylor \& Francis, March 2014.

14 Ibid. 